\title{
Implementation Strategies Preferred by Primary Care Clinicians to Facilitate Cancer Prevention and Control Activities
}

Russell Glasgow ( $\square$ russell.glasgow@cuanschutz.edu )

University of Colorado Denver - Anschutz Medical Campus https://orcid.org/0000-0003-4218-3231

Michaela Brtnikova

University of Colorado

L. Miriam Dickinson

University of Colorado

Jennifer K. Carroll

University of Colorado

Jamie L. Studts

University of Colorado

Research

Keywords: implementation strategies, context, cancer prevention and control, primary

Posted Date: February 28th, 2022

DOI: https://doi.org/10.21203/rs.3.rs-1374193/v1

License: (9) This work is licensed under a Creative Commons Attribution 4.0 International License.

Read Full License 


\section{Abstract}

Introduction: Key stakeholders need to be involved in the identification of feasible and impactful implementation strategies for evidence-based interventions. While a wide range of implementation strategies has been developed, there is little research on their applicability when addressing different cancer prevention and control (CPC) efforts in primary care.

Methods: With an emphasis on rural practices, we conducted a survey of primary care physicians to identify implementation strategies they perceive as most feasible and impactful. The survey included both primary prevention behavior change counseling and cancer screening issues. Analyses contrasted ratings of feasibility and impact across these activities and nine implementation strategies, and among clinicians in different settings with a focus on comparisons between clinicians in rural vs. non-rural settings.

Results: We had 326 respondents from a wide range of practice types, representing four different practice-based research networks, 49 states, and including 177 clinicians in rural settings. Ratings of impact were somewhat higher than those for feasibility. Few of the nine implementation strategies were high on both impact and feasibility. Only 'adapting to my practice' was rated higher than a 4 ("moderate") on both impact and feasibility. There were relatively few differences between rural and non-rural clinicians or associated with other clinician or setting characteristics.

Conclusions: There is considerable variability in perceived impact and feasibility of implementation strategies for CPC activities among primary care clinicians. It is important to assess both feasibility and impact of implementation strategies as well as their generalizability across settings. Our results suggest that optimal strategies to implement evidence-based CPC activities will likely need to be developed or adapted for primary care settings. Future research is needed to replicate these findings with different settings and interventions, and identify practical, stakeholder informed implementation strategies.

\section{Contributions To The Literature}

-Presents a novel and efficient method of obtaining stakeholder input from a large and diverse sample of primary care clinicians

-Reports on both the rated feasibility and impact of different implementation strategies, and importantly their combination to produce an index of overall fit or helpfulness

-Studies the effects of several contextual factors related to ratings of implementation strategies including type of cancer prevention activity, rural vs. non-rural setting, type of primary care practice, and demographics of patients seen.

\section{Introduction}


There is a large gap and time lag between the evidence on effective cancer prevention and control (CPC) strategies and their implementation in diverse clinical settings.(1-4) This is true for both primary prevention and cancer screenings.(5) To design effective, practical programs and strategies to address real world CPC challenges it is important to understand the complex settings in which these interventions and related implementation strategies are to be implemented.(6) Implementation challenges are especially acute in rural primary care settings,(7) which have fewer resources to conduct preventive interventions among patient populations that have many social determinants of health challenges and higher rates of morbidity and mortality. $(8,9)$

To design programs that will have wide uptake, be successfully implemented, and sustained, it is important to include stakeholder engagement in design of appropriate interventions.(10) Key stakeholders need to be involved in the identification of feasible and impactful implementation strategies for evidence based interventions.(11) Although a wide range of implementation strategies have been identified and employed,(12) there is little research on their applicability for different CPC issues or settings.(13) While there has been considerable recent attention to the issue of stakeholder engagement, including clinician involvement in design and adaptation of interventions in primary care, $(6,7)$ and some on stakeholders in rural settings, $(7,14)$ there has been almost no research on clinicians' perspectives on different implementation strategies.

Obtaining stakeholder input on implementation strategies that are both feasible and effective constitutes an important opportunity for both advancing implementation science and for providing pragmatic assistance to practice settings. $(12,15)$ There is a large number of implementation strategies that differ widely on cost, expertise required, etc.(16) We are not aware of comparative data on which strategies are superior or preferred by different types of primary care implementers or practice settings (e.g., rural vs. urban; experienced vs. novice practitioners; large vs. small low resource settings). It is likely(15) that the optimal and preferred strategies will vary by issue, context, and other factors. $(17,18)$ We consider overall helpfulness to be a function of both feasibility and reach, and impact or effectiveness. To achieve improvement in population health, both are needed.

We conducted a clinician survey as part of our $\mathrm{NCl}$ funded Implementation Science Center in Cancer Control (ISC3).(19) The purpose of the Colorado P50 center grant, Pragmatic Implementation Science Approaches to Assess and Enhance Value of Cancer Prevention and Control in Rural Primary Care (COISC3), is to develop, implement, evaluate, and disseminate pragmatic implementation science approaches to cost and value to enhance CPC in rural primary care. We focus especially on tailoring and adapting implementation strategies and intervention approaches to local contexts, populations, settings, and resources.(20)

In summary, it will be useful for both research and practice in CPC, and especially research-practice partnerships, to have information about stakeholder perspectives on which implementation strategies are most feasible and most impactful in general, for different CPC issues, and for particular contexts. To address this issue, we conducted a stakeholder survey of primary care clinicians to 1) identify CPC 
activities with which clinicians would most like assistance; 2) evaluate perceived impact and feasibility of different implementation strategies to assist with delivery of CPC services; and 3) investigate clinician and practice characteristics potentially related to CPC activities with particular focus on rural vs. non-rural comparisons.

\section{Methods}

This study was reviewed by the Colorado Multiple Institutional Review Board at the University of Colorado, approved as expedited research, and written informed consent was not required. This survey was conducted from September to December 2021.

\section{Settings and Target Population}

A national sample of primary care clinicians was obtained from the American Academy of Family Physicians (AAFP) combined with clinicians from four practice-based research networks (PBRNs) which are collaborating with our COISC3 Center. Eligible respondents were adult primary care clinicians including doctors of medicine, doctors of osteopathic medicine, nurse practitioners and physicians' assistants who were providers of record. While the study focused on rural primary care, both rural and non-rural clinicians were surveyed to allow comparisons.

\section{Survey Design and Development}

The survey instrument (see Appendix 1) covered the following conceptual areas: perceived need for assistance to improve various CPC services; preferences for assistance with CPC vs. other types of preventive service activities (this issue is the topic of a separate publication); perceived feasibility and impact of different implementation strategies; and physician and practice characteristics. The survey underwent internal evaluation and revision by members of the investigative team including cancer researchers $(n=5)$, local primary care clinicians $(n=4)$, and PBRN directors having large numbers of rural practices $(n=3)$. The penultimate version was pilot-tested by a group of 5 cancer researchers and practicing primary care physicians from different regions of the country. More detail on the survey design, development, sample and procedures are available elsewhere.(21)

Needs for assistance with CPC activities: To provide context and specificity for rating the implementation strategies, respondents were asked to select one of seven different CPC activities that they 'would most like help with implementing' in their practice. The seven activities included 1) primary prevention behavior change counseling activities (i.e., assessment and counseling on nutrition and diet; physical activity; tobacco use; and HPV vaccine; 2) screening for lung cancer and colorectal cancer; and 3) support for cancer survivorship care.

Implementation strategies: To minimize respondent burden, it was necessary to limit the number of implementation strategies rated. Pilot testing indicated that it was feasible to rate only 8-10 strategies. We selected implementation strategies(12) from different ERIC conceptual categories(22) that were most 
applicable to primary care and preventive services. Items were selected from two sources. First, we selected an item from each of five clusters of Expert Recommendations for Implementing Change (ERIC) strategies identified by Waltz et al.(22) These items were: audit and feedback (from the evaluative and iterative strategies cluster); facilitation (from the interactive assistance cluster); adapt to our practice (from the adapt and tailor to context cluster); training and education for staff (from the train and educate stakeholders cluster); and engage patients (from the engage consumers cluster). Because of our focus on prevention and primary care, we also included items from each of the four categories of implementation strategies identified as used most frequently in the large Evidence Now project that targeted improvement of multiple preventive services in over 200 primary care settings in 12 states.(23) These implementation strategies were: 1) build a health information technology tool; 2) assess and redesign clinic workflow; 3 ) refer patients to community resources; and 4) use a quality improvement approach. Pre-testing, cognitive testing, and piloting activities indicated that it was necessary to slightly modify the wording of some items to fit the vocabulary and understanding of practicing primary care clinicians rather than implementation researchers.

Ratings of feasibility and impact of implementation strategies. Respondents were asked to provide two ratings for each implementation strategy: perceived feasibility and impact. The rationale was that many evidence-based interventions and strategies identified in efficacy and effectiveness research may not be feasible for many settings or populations.(24) Feasibility was defined for respondents as "how easy it would be to conduct this strategy in your practice". Impact was defined as "the effect this strategy would have on facilitating consistent delivery in your practice". Both feasibility and impact were rated on 6-point Likert-type scales. This allowed us to calculate an overall fit (helpfulness) index by multiplying impact and feasibility responses for each item, as well as to create a figure that illustrated the combination of feasibility and impact.

Physician and practice characteristics. Several variables were included for descriptive purposes and as potential moderating factors. Related to our COISC3 Center goals, of greatest a priori interest and a focus of many of our analyses was a classification of rural vs. non-rural clinical settings. Rural status was assessed using zip code of the respondent and the corresponding RUCA codes 4-10.(25) Other respondent and practice characteristics included clinician specialty and gender, number of adult patients seen, years since training, size and type of practice (e.g., federally qualified health center; private practice; hospital system), implementation climate,(26) presence of any disease registries or prompting systems, and estimated age group, insurance type, and race/ethnicity characteristics of their patient population.

Survey Administration. Following Dillman's Tailored Designed Method,(27) all clinicians received an electronic cover letter endorsed by their PBRN or national organization together with a 19-item questionnaire. Those with a known email address received an initial survey using Qualtrics ${ }^{\mathrm{XM}}$ and up to two emailed reminders. Due to rules and mandatory practices regarding surveys in different PBRNs, slightly different follow-up procedures were used after the identical initial mail distribution. Those without an email address received a paper survey sent via standard mail. Email non-responders from two PBRNs also received a mailed survey. Each respondent was offered an incentive of \$50 using RewardsLink. 


\section{Statistical Analyses}

All statistical analyses were performed using SAS software (SAS 9.4, SAS Institute, Cary, NC). Analyses were primarily descriptive and focused on means, standard deviations, and ranges for the implementation strategies. To compare ratings on a) different CPC activities and $b$ ) different strategies (with repeated responses for individuals) general linear mixed effects modeling was used for continuous measures with random effect for individual respondent, adjusted for clinician characteristics that impacted results.(28) As appropriate, chi-square or ANOVA was used to evaluate potential differences associated with continuous or categorical data on physician and practice characteristics.

\section{Results}

Sample

We received a total of 326 eligible surveys. Respondents practiced in 49 states and included 177 rural and 149 non-rural providers. The overall response rate for completed surveys was $4 \%$, after removing those ineligible (e.g., not providers, not practicing in the U.S., not having adult patients; and incomplete responses). Table 1 summarizes overall clinician and practice characteristics and Table 2 displays characteristics by and differences between rural vs. nonrural providers. There was a wide range of practice types, sizes and number of patients seen. Almost half (47\%) of respondents' patient panels were over 50 years of age; an estimated $32 \%$ had Medicare insurance, and $31 \%$ had Medicaid insurance (23\%) or were uninsured. (8\%) Clinicians estimated that $66 \%$ of their patients were non-Hispanic White, $15 \%$ were Latinx, $12 \%$ African American and $5 \%$ or less were Asian and American Indian/Alaskan Natives. 
Table 1

Respondent Characteristics Overall

Overall $(n=326)$

Practice Location, \% (n)

Rural

$54 \%(177)$

Non-rural

$46 \%(149)$

Type of Practice, \% (n)

FQHC

$16 \%(49)$

Private Practice

$38 \%(112)$

Hospital/Health-system Owned

$39 \%(116)$

Academic

$13 \%(40)$

Other (VA, HMO)

$1 \%(4)$

Registry or Prompting System for Cancer Prevention and Control Services, \% (n)

Very Robust

$31 \%(92)$

For Some

$46 \%(139)$

No

$23 \%(68)$

Degree, \% (n)

MD

$77 \%(251)$

DO

$11 \%(37)$

NP

$5 \%(15)$

PA

$4 \%(14)$

Other (eliminated from survey)

$3 \%(9)$

Specialty, \% (n)

Family Physician

91\% (293)

Internal Medicine

$6 \%(19)$

Other

$4 \%(12)$

Gender, \% (n)

$F Q H C=$ Federally Qualified Health Center; $V A=$ Veterans Affairs, $\mathrm{HMO}=$ Health Maintenance Organization; $S D=$ Standard Deviation; $M D=$ Doctor of Medicine; $D O=$ Doctor of Osteopathic medicine; NP = Nurse Practitioner; PA = Physician' Assistant 


\begin{tabular}{|ll|}
\hline & Overall (n= 326) \\
\hline Male & $47 \%(148)$ \\
\hline Female & $53 \%(167)$ \\
\hline Panel Size (patients per week), mean (SD) & $73(103)$ \\
\hline Years from finished clinical training, years (SD) & $20(12)$ \\
\hline Total number of clinical staff members, mean (SD) & $18(19)$ \\
\hline Patient Age, mean \% (SD) & \\
\hline Percent < 18 years old & $13 \%(11)$ \\
\hline Percent 18-50 years old & $39 \%(15)$ \\
\hline Percent > 50 years old & $47 \%(18)$ \\
\hline Patients' Insurance Types, mean \% (SD) & \\
\hline Percent Uninsured & $8 \%(12)$ \\
\hline Percent Medicaid & $23 \%(18)$ \\
\hline Percent Medicare & $32 \%(16)$ \\
\hline Percent Private & $36 \%(21)$ \\
\hline Patient's Race and Ethnicity, mean \% (SD) & \\
\hline Percent White or Caucasian & $5 \% \%(8)$ \\
\hline Percent Hispanic or Latino & $4 \%(9)$ \\
\hline Percent Black or African American & $15 \%(17)$ \\
\hline Percent Asian & $13 \%(16)$ \\
\hline $\begin{array}{l}\text { Percent Other (American Indian, Alaska Native, Native Hawaiian or Pacific } \\
\text { Islander) }\end{array}$ & \\
\hline $\begin{array}{l}\text { FQHC = Federally Qualified Health Center; VA = Veterans Affairs, HMO = Health Maintenance } \\
\text { Organization; SD = Standard Deviation; MD = Doctor of Medicine; DO = Doctor of Osteopathic } \\
\text { medicine; NP = Nurse Practitioner; PA = Physician' Assistant }\end{array}$ \\
\hline
\end{tabular}


Table 2

Respondent Characteristics for Rural and Nonrural Clinicians $(n=326)$

\begin{tabular}{|c|c|c|c|}
\hline & $\begin{array}{l}\text { Rural } \\
n= \\
177\end{array}$ & $\begin{array}{l}\text { Nonrural } \\
n=149\end{array}$ & $\begin{array}{l}\text { p-value* } \\
\text { (rural vs. } \\
\text { nonrural) }\end{array}$ \\
\hline Practice Location, \% (n) & $54 \%$ & $46 \%$ & \\
\hline \multicolumn{4}{|l|}{ Type of Practice ${ }^{a}$, col \% } \\
\hline FQHC & $21 \%$ & $11 \%$ & 0.025 \\
\hline Private Practice & $31 \%$ & $45 \%$ & 0.008 \\
\hline Hospital/Health-system Owned & $45 \%$ & $32 \%$ & 0.019 \\
\hline Academic & $8 \%$ & $20 \%$ & 0.002 \\
\hline Other (VA, HMO) & $4 \%$ & $0 \%$ & 0.179 \\
\hline \multicolumn{3}{|c|}{ Registry or Prompting System for Cancer Prevention and Control Services, col \% } & 0.460 \\
\hline Very Robust & $31 \%$ & $30 \%$ & \\
\hline For Some & $44 \%$ & $50 \%$ & \\
\hline No & $25 \%$ & $20 \%$ & \\
\hline Degree, col \% & & & 0.008 \\
\hline MD & $73 \%$ & $81 \%$ & \\
\hline DO & $10 \%$ & $13 \%$ & \\
\hline NP & $7 \%$ & $2 \%$ & \\
\hline PA & $5 \%$ & $3 \%$ & \\
\hline Other (eliminated from survey) & $5 \%$ & $0 \%$ & \\
\hline \multicolumn{4}{|l|}{ Specialty, col \% } \\
\hline Family Physician & $91 \%$ & $91 \%$ & 0.821 \\
\hline Internal Medicine & $4 \%$ & $8 \%$ & 0.116 \\
\hline
\end{tabular}

FQHC $=$ Federally Qualified Health Center; $V A=$ Veterans Affairs, $H M O=$ Health Maintenance Organization; $\mathrm{SD}=$ Standard Deviation; $\mathrm{MD}=$ Doctor of Medicine; $\mathrm{DO}=$ Doctor of Osteopathic medicine; NP = Nurse Practitioner; PA = Physician' Assistant

${ }^{*}$ Chi-Square for comparison between rural and nonrural $(p<0.05$ in bold)

aType of Practice: percentages within rural and nonrural exceed $100 \%$ because respondents could select all that applied 


\begin{tabular}{|c|c|c|c|}
\hline & $\begin{array}{l}\text { Rural } \\
n= \\
177\end{array}$ & $\begin{array}{l}\text { Nonrural } \\
n=149\end{array}$ & $\begin{array}{l}\text { p-value* } \\
\text { (rural vs. } \\
\text { nonrural) }\end{array}$ \\
\hline Other & $5 \%$ & $1 \%$ & 0.039 \\
\hline Gender, col \% & & & 0.577 \\
\hline Male & $46 \%$ & $48 \%$ & \\
\hline Female & $54 \%$ & $52 \%$ & \\
\hline Panel Size (patients per week), mean (SD) & $\begin{array}{l}67 \\
(45)\end{array}$ & $79(142)$ & 0.328 \\
\hline Years from finished clinical training, years (SD) & $\begin{array}{l}18 \\
(12)\end{array}$ & $22(12)$ & 0.005 \\
\hline Total number of clinical staff members, mean (SD) & $\begin{array}{l}17 \\
(19)\end{array}$ & $19(19)$ & 0.339 \\
\hline \multicolumn{4}{|l|}{ Patient Age, mean \% (SD) } \\
\hline Percent $<18$ years old & $\begin{array}{l}13 \\
(10)\end{array}$ & $14(12)$ & 0.780 \\
\hline Percent $18-50$ years old & $\begin{array}{l}37 \\
(16)\end{array}$ & $42(15)$ & 0.018 \\
\hline Percent $>50$ years old & $\begin{array}{l}49 \\
(19)\end{array}$ & $44(17)$ & $(0.012)$ \\
\hline \multicolumn{4}{|l|}{ Patients' Insurance Types, mean \% (SD) } \\
\hline Percent Uninsured & $\begin{array}{l}8 \\
(11)\end{array}$ & $8(13)$ & 0.881 \\
\hline Percent Medicaid & $\begin{array}{l}25 \\
(18)\end{array}$ & $22(18)$ & 0.132 \\
\hline Percent Medicare & $\begin{array}{l}36 \\
(17)\end{array}$ & $29(13)$ & 0.0002 \\
\hline Percent Private & $\begin{array}{l}32 \\
(19)\end{array}$ & $41(22)$ & 0.0004 \\
\hline
\end{tabular}

FQHC = Federally Qualified Health Center; VA $=$ Veterans Affairs, $\mathrm{HMO}=$ Health Maintenance Organization; $\mathrm{SD}=$ Standard Deviation; $\mathrm{MD}=$ Doctor of Medicine; $\mathrm{DO}=$ Doctor of Osteopathic medicine; NP = Nurse Practitioner; PA = Physician' Assistant

${ }^{*}$ Chi-Square for comparison between rural and nonrural $(p<0.05$ in bold $)$

aType of Practice: percentages within rural and nonrural exceed $100 \%$ because respondents could select all that applied 


\begin{tabular}{|c|c|c|c|}
\hline & $\begin{array}{l}\text { Rural } \\
n= \\
177\end{array}$ & $\begin{array}{l}\text { Nonrural } \\
n=149\end{array}$ & $\begin{array}{l}\text { p-value* } \\
\text { (rural vs. } \\
\text { nonrural) }\end{array}$ \\
\hline Percent White or Caucasian & $\begin{array}{l}72 \\
(22)\end{array}$ & $60(24)$ & $<.0001$ \\
\hline Percent Hispanic or Latino & $\begin{array}{l}14 \\
(16)\end{array}$ & $17(19)$ & 0.142 \\
\hline Percent Black or African American & $\begin{array}{l}8 \\
(13)\end{array}$ & $17(18)$ & $<0.0001$ \\
\hline Percent Asian & $4(8)$ & $6(7)$ & 0.014 \\
\hline $\begin{array}{l}\text { Percent Other (American Indian, Alaska Native, Native Hawaiian } \\
\text { or Pacific Islander) }\end{array}$ & $\begin{array}{l}5 \\
(11)\end{array}$ & $3(5)$ & 0.084 \\
\hline \multicolumn{4}{|c|}{$\begin{array}{l}\text { FQHC = Federally Qualified Health Center; } \mathrm{VA}=\text { = Veterans Affairs, } \mathrm{HMO}=\text { = Health Maintenance } \\
\text { Organization; SD = Standard Deviation; MD = Doctor of Medicine; DO = Doctor of Osteopathic } \\
\text { medicine; NP = Nurse Practitioner; PA = Physician' Assistant }\end{array}$} \\
\hline \multicolumn{4}{|c|}{${ }^{*}$ Chi-Square for comparison between rural and nonrural $(p<0.05$ in bold) } \\
\hline
\end{tabular}

Need for assistance across CPC areas. Thirty two percent of clinicians chose nutrition and diet as the CPC area in which they would most like help; $16 \%$ chose lung cancer screening; $12 \%$ chose each of physical activity, colorectal cancer screening, and cancer survivorship support, $11 \%$ chose tobacco use assessment and counseling and 5\% HPV discussion. There were no differences on which CPC activity assistance was selected as most desired between clinicians in rural and non-rural settings.

Ratings of implementation strategies

Impact. In general, the various implementation strategies were rated as having moderate impact as summarized in Table 3 ( $M=3.95$ on the 6-point scale). Three of the strategies - 'Engaging patients for tailoring' ( $M=4.32)$, 'Adapting to our practice' $(M=4.17)$, and 'Training and education' $(M=4.12)$ had more than moderate impact (>than 4 ). Referring patients to community resources was rated as having little impact, especially among rural clinicians. There was moderate variability on impact ratings within and across the implementation strategies. 
Table 3

Means and Standard Deviations on Ratings of Impact, Feasibility and Overall Fit by Rural and Nonrural Status $(n=326)$

\begin{tabular}{|c|c|c|c|c|c|c|}
\hline \multirow[t]{3}{*}{ Implementation strategy } & \multirow{2}{*}{\multicolumn{2}{|c|}{$\begin{array}{l}\text { Impact } \\
\text { Mean (SD) }\end{array}$}} & \multirow{2}{*}{\multicolumn{2}{|c|}{$\begin{array}{l}\text { Feasibility } \\
\text { Mean (SD) }\end{array}$}} & \multirow{2}{*}{\multicolumn{2}{|c|}{$\begin{array}{l}\text { Fit } \\
\text { Mean (SD) }\end{array}$}} \\
\hline & & & & & & \\
\hline & Rural & Nonrural & Rural & Nonrural & Rural & Nonrural \\
\hline Assess and redesign clinic workflow & $\begin{array}{l}3.73 \\
(1.42)\end{array}$ & $\begin{array}{l}3.91 \\
(1.22)\end{array}$ & $\begin{array}{l}3.25 \\
(1.30)\end{array}$ & $\begin{array}{l}3.42 \\
(1.23)\end{array}$ & $\begin{array}{l}13.16 \\
(8.64)\end{array}$ & $\begin{array}{l}14.31 \\
(8.15)\end{array}$ \\
\hline Have a practice facilitator or coach & $\begin{array}{l}3.87 \\
(1.46)\end{array}$ & $\begin{array}{l}4.17 \\
(1.33)\end{array}$ & $\begin{array}{l}2.94 \\
(1.55)\end{array}$ & $\begin{array}{l}3.05 \\
(1.53)\end{array}$ & $\begin{array}{l}12.46 \\
(9.24)\end{array}$ & $\begin{array}{l}13.65 \\
(9.13)\end{array}$ \\
\hline $\begin{array}{l}\text { Refer patients to community } \\
\text { resources (e.g., WIC, YMCA, Quitline) }\end{array}$ & $\begin{array}{l}3.21 \\
(1.33)\end{array}$ & $\begin{array}{l}3.62 \\
(1.31)\end{array}$ & $\begin{array}{l}3.29 \\
(1.39)\end{array}$ & $\begin{array}{l}3.75 \\
(1.35)\end{array}$ & $\begin{array}{l}11.50 \\
(7.70)\end{array}$ & $\begin{array}{l}14.65 \\
(8.86)\end{array}$ \\
\hline Use a quality improvement approach & $\begin{array}{l}3.96 \\
(1.20)\end{array}$ & $\begin{array}{l}4.06 \\
(1.18)\end{array}$ & $\begin{array}{l}3.97 \\
(1.32)\end{array}$ & $\begin{array}{l}3.94 \\
(1.27)\end{array}$ & $\begin{array}{l}16.62 \\
(8.51)\end{array}$ & $\begin{array}{l}17.08 \\
(8.98)\end{array}$ \\
\hline $\begin{array}{l}\text { Training and education for practice } \\
\text { staff }\end{array}$ & $\begin{array}{l}4.13 \\
(1.20)\end{array}$ & $\begin{array}{l}4.11 \\
(1.21)\end{array}$ & $\begin{array}{l}3.87 \\
(1.28)\end{array}$ & $\begin{array}{l}4.05 \\
(1.22)\end{array}$ & $\begin{array}{l}16.66 \\
(8.44)\end{array}$ & $\begin{array}{l}17.32 \\
(8.28)\end{array}$ \\
\hline $\begin{array}{l}\text { Adapt evidence-based intervention } \\
\text { (or guideline) to our practice }\end{array}$ & $\begin{array}{l}4.18 \\
(1.17)\end{array}$ & $\begin{array}{l}4.16 \\
(1.19)\end{array}$ & $\begin{array}{l}4.18 \\
(1.16)\end{array}$ & $\begin{array}{l}4.26 \\
(1.17)\end{array}$ & $\begin{array}{l}17.95 \\
(7.99)\end{array}$ & $\begin{array}{l}18.42 \\
(8.29)\end{array}$ \\
\hline $\begin{array}{l}\text { Use audit and feedback or some type } \\
\text { of periodic data reporting }\end{array}$ & $\begin{array}{l}3.70 \\
(1.22)\end{array}$ & $\begin{array}{l}3.82 \\
(1.24)\end{array}$ & $\begin{array}{l}3.65 \\
(1.27)\end{array}$ & $\begin{array}{l}3.44 \\
(1.18)\end{array}$ & $\begin{array}{l}14.29 \\
(7.87)\end{array}$ & $\begin{array}{l}13.99 \\
(7.83)\end{array}$ \\
\hline $\begin{array}{l}\text { Engage patients to help create an } \\
\text { individually tailored action plan }\end{array}$ & $\begin{array}{l}4.34 \\
(1.21)\end{array}$ & $\begin{array}{l}4.30 \\
(1.21)\end{array}$ & $\begin{array}{l}3.77 \\
(1.17)\end{array}$ & $\begin{array}{l}3.72 \\
(1.21)\end{array}$ & $\begin{array}{l}16.93 \\
(8.10)\end{array}$ & $\begin{array}{l}16.79 \\
(8.31)\end{array}$ \\
\hline $\begin{array}{l}\text { Build a health information } \\
\text { technology tool (e.g., EHR reminder } \\
\text { or decision aid) }\end{array}$ & $\begin{array}{l}3.94 \\
(1.39)\end{array}$ & $\begin{array}{l}3.92 \\
(1.36)\end{array}$ & $\begin{array}{l}3.33 \\
(1.44)\end{array}$ & $\begin{array}{l}3.42 \\
(1.38)\end{array}$ & $\begin{array}{l}13.96 \\
(8.86)\end{array}$ & $\begin{array}{l}14.18 \\
(8.13)\end{array}$ \\
\hline Overall Mean across all strategies & 3.90 & 4.01 & 3.58 & 3.67 & 14.84 & 15.60 \\
\hline & & & & & $(6.32)$ & $(6.30)$ \\
\hline
\end{tabular}

After forming subgroups based on the CPC activity chosen, we compared average ratings on impact among categories of 1) primary prevention (nutrition, physical activity, smoking cessation, or HPV counseling), 2) cancer screening (lung, colorectal) and 3) cancer survivorship support. Although average impact ratings were slightly lower among those selecting cancer survivorship ( $M=3.74$ vs. 4.02 for primary prevention activities and 3.90 for cancer screening), these differences were not significant.

There were no differences between rural and non-rural clinicians with the exception that the impact of referral to community resources was rated significantly lower in rural than non-rural practices $(p<.008)$. Exploratory subgroup analyses evaluating the impact of other practice characteristics indicated that only gender was significant: females rated the implementation strategies as having higher impact $(p<.03)$ 
than males. Inclusion of gender in the analysis did not alter results concerning rural-non-rural comparisons.

Feasibility. Ratings of feasibility ( $M=3.62)$ were lower than those for impact, with the exceptions of making adaptions to one's practice and referral to community resources (Table 3). The implementation strategy rated as the most feasible was adapting to local context. Practice facilitation was rated as the least feasible strategy, especially for rural clinicians. Once again there was considerable variability across clinicians for the same strategy, suggesting that contextual factors may be important. There were few meaningful differences on feasibility ratings between rural and non-rural clinicians. Rural clinicians did rate the strategy of community referrals as less feasible than non-rural clinicians ( $M$ of 3.3 vs. 3.8, p $<.004)$. Of other potential moderating clinician, practice, and patient population characteristics the only significant effect was that clinicians serving a higher percentage of uninsured patients rated implementation strategies as less feasible $(p<.03)$. Inclusion of this variable in the analysis did not alter results concerning rural-non-rural comparisons.

Although average feasibility ratings were lower among those selecting cancer survivorship as their top area of need ( $M=3.30$ vs. 3.68 for primary prevention activities and 3.66 for cancer screening), these differences were not significant.

Overall fit. To evaluate the overall helpfulness of implementation strategies, we calculated an overall 'fit to context' score by multiplying the feasibility and impact ratings for each strategy as seen in the righthand columns of Table 3. These scores could range between 1 and 36 and as can be seen, most scores were in the middle to lower range of possible scores: a score of moderate on both feasibility and impact would result in a score of 16 . These scores as well as the scatter plot diagram divided into quadrants in Fig. 1 illustrate that only four strategies: adaptations to local practice; training and education; quality improvement; and engaging patients for tailoring received relatively strong fit scores $(>16)$. The correlation between rated feasibility and impact was .68 $(p<.001)$.

Clinician and practice characteristics related to Fit scores were similar to those observed for Impact and Feasibility scores. The only difference between rural and non-rural clinicians was on community referrals with rural clinicians having significantly lower Fit scores than non-rural $(p<001)$. No other clinician or practice characteristics were related to overall Fit scores.

Average FIT scores were marginally lower $(p<.06)$ for respondents selecting cancer survivorship as their top area of need for assistance $(M=13.4)$ vs. primary prevention activities $(M=15.6)$ or cancer screening $(M=15.2)$.

Figure 1 presents a scatterplot illustrating mean ratings of results for impact and feasibility. As can be seen, only the strategy of adapting evidence based intervention or guideline to practice had a mean rating falling into the upper right quadrant of having both moderate or greater impact and feasibility. Four strategies- referring patients to community resources; using audit and feedback or periodic reporting; 
building a health information technology tool; and assessing and redesigning clinic workflow had mean ratings falling into the bottom left quadrant of less than moderate ratings on both impact and feasibility.

\section{Discussion}

This study adds to the literature on clinician perspectives on CPC areas in which clinicians desire assistance. It also advances the implementation science literature on the characteristics and practicality of implementation strategies in the primary care context. In general, the strategies were rated as higher on impact than feasibility. An important recommendation for future research is to consider the combination of both feasibility and impact for selecting implementation strategies. This issue is similar to the broader issue of considering level of adoption and reach of interventions in addition to their clinical effectiveness $(24,29,30)$ to impact population health.

Few of the nine implementation strategies were high on both impact and feasibility, suggesting that optimal strategies to implement evidence-based CPC activities will likely need to be developed or adapted for primary care settings. Only 'adapting to my practice' was rated higher than a 4 ("moderate") on both impact and feasibility. In contrast, some of the strategies such as practice facilitation were not viewed as feasible, especially in rural settings. Referring patients to community resources was not seen as either feasible or impactful, especially in rural settings, possibly reflecting the relative dearth of CPC resources in these settings.

There was moderate variability on ratings of each implementation strategy. Respondents used the entire $1-6$ range in rating the feasibility and impact of all the strategies. With few exceptions this variability was not explained by rural vs. non-rural differences, type of CPC activity being rated, or other clinician, practice, or patient populations factors. This study investigated only a handful of quantitative practice and clinician characteristics: more investigation of context- and changing context(31) is needed. It may also be that 'micro-tailoring' is needed: that there is not one category of strategies that is generally more preferred, but that strategies need to be selected in each practice to deal with practice-specific contexts.

This research is an important early step in identifying implementation strategies likely to be most useful for delivering evidence-based CPC services in primary care. Other steps could include 1) evaluating if actual 'observed feasibility' (implementation consistency) and impact (effectiveness) are similar to these clinician ratings of projected impact and feasibility $(32,33)$ and 2$)$ investigating additional ERIC strategies $(12,22)$ or those created by practice teams. Implementing and studying CPC activities in primary care is a challenging undertaking, including complexities such as that context, personnel, competing demands, and implementation strategies often change over time,(34) and strategies are often used in combinations or strategy bundles.(35) Thus, sequential or contingent selection and tracking of strategies may be important.

This report has several strengths and some limitations. Its strengths include the moderately large sample size and especially the good sized sample of rural primary care clinicians; a variety of practice types, clinician and patient panel characteristics; the random order of presentation of implementation strategies 
across respondents to control for potential order effects; inclusion of strategies from multiple ERIC categories and those found be applicable in primary care settings;(23) and comparison of results for primary prevention, cancer screening and survivorship support activities. We were also able to conduct some subgroup comparisons, especially those relevant to rural-non-rural differences for which there are often insufficient sample sizes to conduct such analyses.

Key limitations include the relatively low survey return rate despite following many best survey research practices recommended by Dillman(27) and others,(36) inclusion of signed, strong letters of support from PBRN leaders and a $\$ 50$ stipend. This return rate and possibly the observed ratings may be due at least in part to the challenges of coping with COVID-19 and in some cases even the tenuous continued existence of the practices of the clinicians surveyed. Consequently, this is not a representative national sample; is composed primarily family physicians; and does not represent the perspectives of patients, internal medicine physicians or other practitioners (e.g., PAs and NPs who deliver many services in some rural and low resource practices).

Although we have hypotheses concerning why the observed pattern of results was obtained, without supporting qualitative data or experimental tests of such interpretations we cannot be confident in these explanations. There was also considerable variability across clinicians, suggesting that there may be other unmeasured contextual factors that influenced our results.

\section{Conclusions}

This study obtained clinician stakeholder perspectives on the feasibility and estimated impact of different implementation strategies. Impact ratings were moderate and feasibility ratings slightly lower across a variety of CPC activities, clinicians and types of primary care settings. There were few differences observed between clinicians in rural and non-rural settings on feasibility, impact, or overall 'fit' of strategies, despite the well documented challenges of rural CPC. $(8,9)$ Future research is needed to replicate these findings with different settings and populations, including other types of preventive service activities and implementation strategies.

\section{Abbreviations}

$\mathrm{CPC}$

cancer prevention and control

ISC3

Implementation Science Center in Cancer Control COISC3

Colorado P50 center grant, Pragmatic Implementation Science Approaches to Assess and Enhance Value of Cancer Prevention and Control in Rural Primary Care

AAFP

American Academy of Family Physicians

Page 15/20 
PBRNs

practice-based research networks

ERIC

Expert Recommendations for Implementing Change

$M$

mean

HPV

human papillomavirus

ANOVA

analysis of variance

MD

Doctor of Medicine

DO

Doctor of Osteopathic medicine

PA

Physician's Assistant

NP

Nurse Practitioner

\section{Declarations}

Ethics approval and consent to participate: This study was approved as expedited by the Colorado Multiple Institutional Review Board, protocol number 19-1706.

Consent for publication: Not applicable

Availability of data and materials: The datasets during and/or analyzed during the current study available from the corresponding author on reasonable request.

Competing interests: Dr. Studts has provided compensated consultation to the J\&J Lung Cancer Initiative, uncompensated consultation to Genentech, and serves on a Medical Advisory Board for the Lung Ambition Alliance, supported by AstraZeneca. None of the other authors have conflict of interest.

Funding: This study was partially supported by NCI Implementation Science Center grant P50CA244688 and Comprehensive Cancer Center grant P30CA046934. The funder did not participate in the design of the study and collection, analysis, and interpretation of data and in writing the manuscript.

Authors' contributions: RG participated in Conceptualization, Methodology, Formal analysis, Writing Original Draft, Writing - Review \& Editing, Supervision, Funding acquisition. MB participated in Conceptualization, Methodology, Formal analysis, Investigation, Resources, Writing - Original Draft, Writing - Review \& Editing, Visualization, Supervision, Project administration. LMD participated in Conceptualization, Methodology, Formal analysis, Writing - Original Draft, Writing - Review \& Editing. JC 
participated in Methodology, Investigation, Resources, Writing - Review \& Editing, Project administration. JS participated in Conceptualization, Methodology, Writing - Review \& Editing.

\section{References}

1. Sauer AG, Siegel RL, Jemal A, Fedewa SA. Updated Review of Prevalence of Major Risk Factors and Use of Screening Tests for Cancer in the United States. Cancer Epidemiol Biomarkers Prev. 2017;26(8):1192-208.

2. Hall IJ, Tangka FKL, Sabatino SA, Thompson TD, Graubard BI, Breen N. Patterns and Trends in Cancer Screening in the United States. Prev Chronic Dis. 2018;15:E97.

3. Khan S, Chambers D, Neta G. Revisiting time to translation: implementation of evidence-based practices (EBPs) in cancer control. Cancer Causes Control. 2021;32(3):221-30.

4. Neta G. Ensuring the Value of Cancer Research: Opportunities in Implementation Science. Trends Cancer. 2021;7(2):87-9.

5. Fisher EB, Fitzgibbon ML, Glasgow RE, Haire-Joshu D, Hayman LL, Kaplan RM, et al. Behavior matters. Am J Prev Med. 2011;40(5):e15-30.

6. Luig T, Asselin J, Sharma AM, Campbell-Scherer DL. Understanding Implementation of Complex Interventions in Primary Care Teams. J Am Board Fam Med. 2018;31(3):431-44.

7. Saman DM, Walton KM, Harry ML, Asche SE, Truitt AR, Henzler-Buckingham HA, et al. Understanding primary care providers' perceptions of cancer prevention and screening in a predominantly rural healthcare system in the upper Midwest. BMC Health Serv Res. 2019;19(1):1019.

8. Charlton M, Schlichting J, Chioreso C, Ward M, Vikas P. Challenges of Rural Cancer Care in the United States. Oncol (Williston Park). 2015;29(9):633-40.

9. Blake KD, Moss JL, Gaysynsky A, Srinivasan S, Croyle RT. Making the Case for Investment in Rural Cancer Control: An Analysis of Rural Cancer Incidence, Mortality, and Funding Trends. Cancer Epidemiol Biomarkers Prev. 2017;26(7):992-7.

10. Brownson RCCG, Proctor EK. Dissemination and implementation science in health: Translating research to practice. 2nd Edition ed. New York: Oxford University Press; 2018.

11. Meissner P, Cottler LB, Eder MM, Michener JL. Engagement science: The core of dissemination, implementation, and translational research science. J Clin Transl Sci. 2020;4(3):216-8.

12. Powell BJ, Waltz TJ, Chinman MJ, Damschroder LJ, Smith JL, Matthieu MM, et al. A refined compilation of implementation strategies: results from the Expert Recommendations for Implementing Change (ERIC) project. Implement Sci. 2015;10:21.

13. Rabin B, Glasgow RE. An implementation science perspective on psychological science and cancer: what is known and opportunities for research, policy, and practice. Am Psychol. 2015;70(2):211-20.

14. Harry ML, Saman DM, Truitt AR, Allen Cl, Walton KM, O'Connor PJ, et al. Pre-implementation adaptation of primary care cancer prevention clinical decision support in a predominantly rural healthcare system. BMC Med Inform Decis Mak. 2020;20(1):117. 
15. Powell BJ, Beidas RS, Lewis CC, Aarons GA, McMillen JC, Proctor EK, et al. Methods to Improve the Selection and Tailoring of Implementation Strategies. J Behav Health Serv Res. 2017;44(2):177-94.

16. Proctor EK, Powell BJ, McMillen JC. Implementation strategies: recommendations for specifying and reporting. Implement Sci. 2013;8:139.

17. Chambers DA, Glasgow RE, Stange KC. The dynamic sustainability framework: addressing the paradox of sustainment amid ongoing change. Implement Sci. 2013;8:117.

18. Waltz TJ, Powell BJ, Fernandez ME, Abadie B, Damschroder LJ. Choosing implementation strategies to address contextual barriers: diversity in recommendations and future directions. Implement Sci. 2019;14(1):42.

19. Oh A, Vinson CA, Chambers DA. Future directions for implementation science at the National Cancer Institute: Implementation Science Centers in Cancer Control. Transl Behav Med. 2021;11(2):669-75.

20. Shelton RC, Chambers DA, Glasgow RE. An Extension of RE-AIM to Enhance Sustainability: Addressing Dynamic Context and Promoting Health Equity Over Time. Front Public Health. 2020;8:134.

21. Brtnikova M, Studts JL, Robertson E, Dickinson LM, Carroll JK, Krist AH, et al. Priorities for Improvement Across Cancer and Non-cancer Related Preventive Services Among Rural and Non-rural Clinicians. Cancer Epidemiology, Biomarkers \& Prevention. 2022;Submitted.

22. Waltz TJ, Powell BJ, Matthieu MM, Damschroder LJ, Chinman MJ, Smith JL, et al. Use of concept mapping to characterize relationships among implementation strategies and assess their feasibility and importance: results from the Expert Recommendations for Implementing Change (ERIC) study. Implement Sci. 2015;10:109.

23. Perry CK, Damschroder LJ, Hemler JR, Woodson TT, Ono SS, Cohen DJ. Specifying and comparing implementation strategies across seven large implementation interventions: a practical application of theory. Implement Sci. 2019;14(1):32.

24. Glasgow RE, Emmons KM. How can we increase translation of research into practice? Types of evidence needed. Annu Rev Public Health. 2007;28:413-33.

25. Department of Agriculture US. ERS. Rural-Urban Commuting Area Codes. U.S. Department of Agriculture Economic Research Service2010 [updated 8/17/2020. Available from: https://www.ers.usda.gov/data-products/rural-urban-commuting-area-codes.aspx..

26. Jacobs SR, Weiner BJ, Bunger AC. Context matters: measuring implementation climate among individuals and groups. Implement Sci. 2014;9:46.

27. Dillman DA, Christian LM. Internet, Phone, Mail, and Mixed-Mode Surveys: The Tailored Design Method, 4th Edition. Indianapolis, IN: John Wiley \& Sons Inc.; 2014.

28. Ramon C. Littell GAM, Walter W, Stroup, Russell D, Wolfinger. SAS System for Mixed Models. 2nd ed. Cary: SAS Institute, Inc.; 1999. 656 p.

29. Glasgow RE. What types of evidence are most needed to advance behavioral medicine? Ann Behav Med. 2008;35(1):19-25. 
30. Glasgow RE, Brownson RC, Kessler RS. Thinking about health-related outcomes: what do we need evidence about? Clin Transl Sci. 2013;6(4):286-91.

31. Pfadenhauer LM, Gerhardus A, Mozygemba K, Lysdahl KB, Booth A, Hofmann B, et al. Making sense of complexity in context and implementation: the Context and Implementation of Complex Interventions (CICl) framework. Implement Sci. 2017;12(1):21.

32. Damschroder LJ, Reardon CM, Opra Widerquist MA, Lowery J. Conceptualizing outcomes for use with the Consolidated Framework for Implementation Research (CFIR): the CFIR Outcomes Addendum. Implement Sci. 2022;17(1):7.

33. Reilly KL, Kennedy S, Porter G, Estabrooks P. Comparing, Contrasting, and Integrating Dissemination and Implementation Outcomes Included in the RE-AIM and Implementation Outcomes Frameworks. Front Public Health. 2020;8:430.

34. Kirk MA, Moore JE, Wiltsey Stirman S, Birken SA. Towards a comprehensive model for understanding adaptations' impact: the model for adaptation design and impact (MADI). Implement Sci. 2020;15(1):56.

35. Miller CJ, Wiltsey-Stirman S, Baumann AA. Iterative Decision-making for Evaluation of Adaptations (IDEA): A decision tree for balancing adaptation, fidelity, and intervention impact. J Community Psychol. 2020;48(4):1163-77.

36. Brtnikova M, Crane LA, Allison MA, Hurley LP, Beaty BL, Kempe A. A method for achieving high response rates in national surveys of U.S. primary care physicians. PLoS ONE. 2018;13(8):e0202755.

\section{Figures}




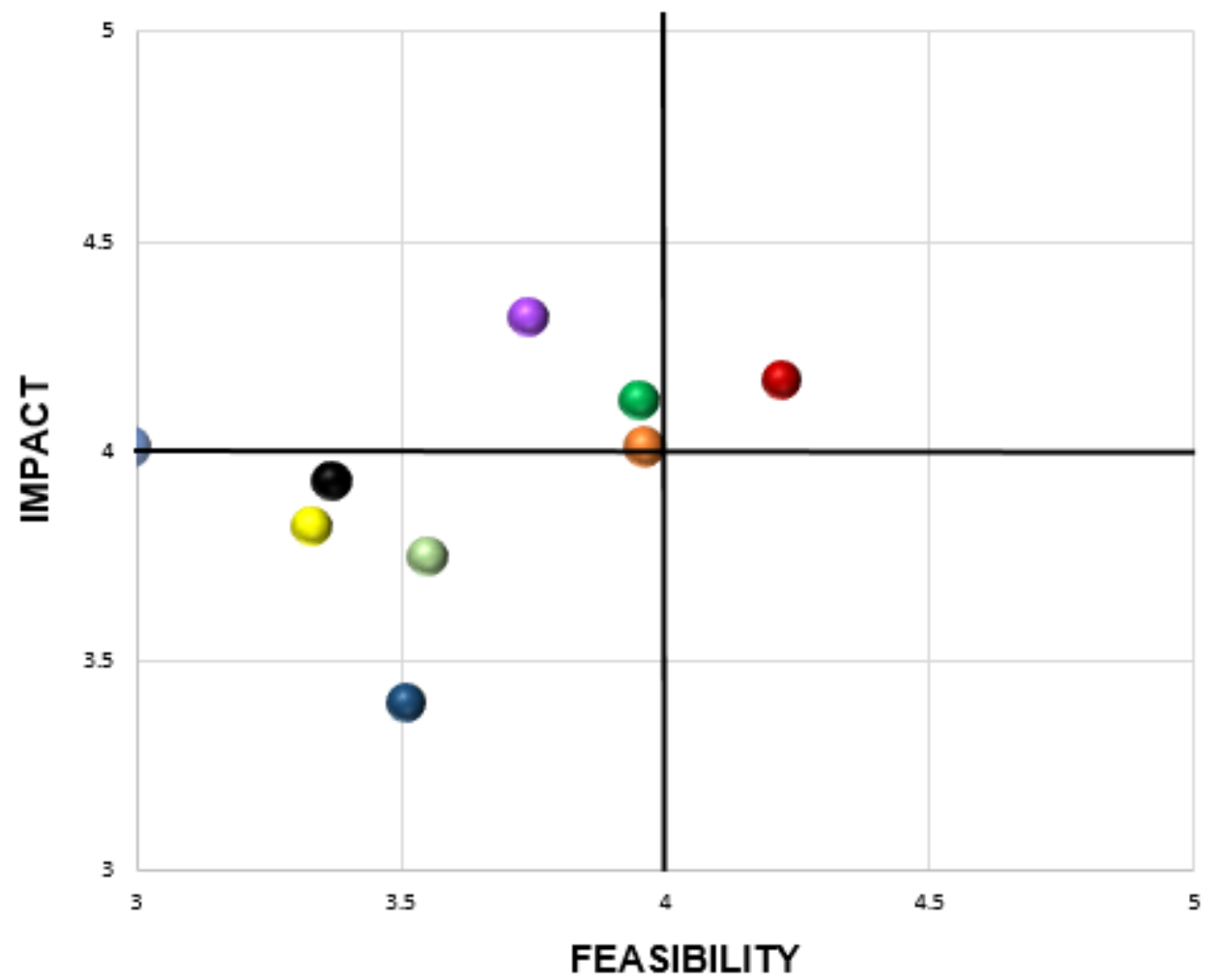

Assessing and redesigning clinic workflow

Using a quality improvement approach

Engaging patients to help create an individually tailored action plan

Training and education for practice staff

Having a practice facilitator coach

Building a health information technology tool

Referring patients to community resources

Adapting evidence-based intervention (or guideline) to practice

$\bigcirc$ Using audit and feedback or periodic data reporting

Figure 1

Scatter Plot of Mean Ratings of Implementation Strategies on Impact and Feasibility $(n=326)$

\section{Supplementary Files}

This is a list of supplementary files associated with this preprint. Click to download.

- Appendix1.docx 